\title{
SOSIALISASI OLAHRAGA TRADISIONAL UNTUK MENINGKATKAN KEBUGARAN DAN MINAT SISWA SD TERHADAP PEMBELAJARAN OLAHRAGA DI WILAYAH KECAMATAN TAMANSARI
}

\author{
Rahmat Permana ${ }^{1}$, M. Fahmi Nugraha ${ }^{2}$, Anggia Suci Pratiwi ${ }^{3}$, \\ Budi Hendrawan ${ }^{4}$, Meiliana Nurfitriani ${ }^{5}$, Yopa Taufik Shaleh ${ }^{6}$ \\ ${ }^{123456}$ Universitas Muhammadiyah Tasikmalaya \\ Email: rahmat.pgsd@umtas.ac.id ${ }^{1}$,m.fahminugraha@umtas.ac.id ${ }^{2}$, \\ anggia@umtas.ac.id ${ }^{3}$, hendrawan_budy@umtas.ac.id ${ }^{4}$, \\ meiliana.nurfitriani@umtas.ac.id ${ }^{5}$,yopa_4474@yahoo.co.id ${ }^{6}$
}

\begin{abstract}
ABSTRAK
Pembelajaran olahraga di Sekolah Dasar perlu berorientasi pada minat dan kesenangan dalam melakukan aktivitas fisik, orientasi belajar gerak khusus untuk meningkatkan keterampilan satu kecabangan olahraga tidak bisa dilakukan di Sekolah Dasar. Pelaksanaan keterampilan kecabangan berpotensi menurunkan motivasi dalam bergerak. Olahraga tradisional di indonesia belum terlalu gencar dilaksanakan. khususnya di daerah Tasikmalaya olahraga ini terkadang oleh guru kurang diberi perhatian lebih akibatnya berdampak pada peserta didik yang kehilangan motivasi berolahraga, motivasi bergerak dan kesadaran olahraga secara mandiri belum tercipta. Karena anak tidak pernah mengalami pengalaman belajar gerak yang menyenangkan. Dalam PENGMAS Program Studi PGSD akan menerapkan program pendidikan olahraga berbasis permainan untuk anak SD di kecamatan tamansari kota Tasikmalaya. Adapun metode tersebut merupakan hasil penelitian bahwa permainan tradisional berpengaruh signifikan terhadap pengembangan motorik kasar dan peningkatan level kebugaran jasmani anak pada kategori usia SD. Tujuan dari pengabdian ialah meningkatkan minat terhadap pembelajaran olahraga, meningkatkan level kebugran anak SD di kecamatan tamansari dan memperkenalkan olahraga tradisional sebagai alat untuk melestarikan kebudayaan masyarakat Jawa Barat khususnya kepada generasi penerus bangsa yaitu anak SD. Metode permainan olahraga tradisional dilakukan dengan metode Play-Teach-Play yang disisipkan pada tahap pelaksanaan pemanasan olahraga sebelum masuk ke dalam materi inti.
\end{abstract}

Kata Kunci: Kebugaran, Minat, Olahraga Tradisional

\begin{abstract}
The learning of sports in elementary schools needs to be oriented to the interests and enjoyment of physical activity, the specific motion-learning orientation to improve the skills of one sport branch can not be done in elementary school. Implementation of skeletal skills potentially lowers motivation in moving. Traditional sports in Indonesia have not been too heavily implemented. especially in the Tasikmalaya area of this sport sometimes by less teachers given more attention consequently impact on learners who lose motivation to exercise, motivation to move and awareness of the sport independently has not been created. Because the child has never had a fun learning experience. In PENGMAS PGSD Study Program will implement game-based sports education program for elementary school children in Tasikmalaya city park district. The method is the result of research that the traditional game has a significant effect on the development of gross motor and increase the level of physical fitness of children in elementary school age category. The purpose of the devotion is to increase the interest in sports learning, increase the level of kebugran elementary school children in Tamansari district and introduce traditional sports as a tool to preserve the culture of the people of West Java, especially to the next generation of elementary school children. Traditional sports game methods are performed using the Play-Teach-Play method that is inserted at the stage of exercise warming before entering into the core material.
\end{abstract}

Keywords: Fitness, Interests, Traditional Sport 


\section{PENDAHULUAN}

Usia SD merupakan usia produktif untuk melaksanakan segala kegiatan yang bersifat gerak fisik, karena memang pada saat usia produktif tubuh seseorang masih siap untuk menerima segala macam aktivitas dari yang sedang maupun berat. Akan tetapi terdapat masalah yang serius. Pertama, olahraga yang membosankan sering sekali membuat anak SD tidak termotivasi untuk melakukan olahraga sehiingga level kebugaran semakin menurun dan mengakibatkan aktivitas gerak berkurang. kedua, fasilitas lapangan yang kurang memadai menurunkan motivasi untuk berolahraga.

Program olahraga yang membosankan bisa terjadi di kalangan anak SD apabila tidak dibina oleh guru ataupun pendidik yang mengerti tentang program olahraga. Anak sering melakukan lari berkeliling lapangan untuk mencapai kebugaran. dari beberapa hasil wawancara dengan guru olahraga dan peserta didik disimpulkan bahwa terasa bosan dan jenuh apabila olahraga hanya sekedar berlari ataupun melakukan latihan kekuatan (sit up, push up) tentu saja ini akan menjadi masalah yang berdampak pada penurunan kualitas kebugaran anak SD di kecamatan tamansari.

Rendahnya kebugaran anak SD kecamatan tamansari terletak pada mutu layanan pendidikan olahraga berupa kegiatan olahraga yang terprogram dengan baik sehingga tidak membuat pelakunya jenuh atau bosan. Mutu fasilitas dari mulai alat olahraga, khususnya olahraga masal sangat kurang seperti bola futsal, voli dan lapangan sulit ditemukan. Adapun tujuan dari pengabdian masyarakat yang dilakukan ialah mampu meningkatkan minat berolahraga dan menyukai pelajaran Pendidikan Jasmani.

Rendahnya mutu pelayanan pendidikan olahraga yang bersifat menyenangkan tentu akan membuat penurunan pada level kebugaran serta tidak ada kesadaran untuk melakukan aktivitas olahraga secara mandiri permasalahan pertama mitra tentu saja tidak akan langsung selesai tapi minimal bisa bertahap diselasaikan dengan cara memberikan satu program layanan pendidikan olahraga berupa permainan tradisional. Pengenalan permainan tradisional akan menumbuhkan motivasi berolahraga yang tinggi serta kesadaran olahraga secara mandiri dapat meningkat sehingga level kebugaran akan naik dengan sendirinya.

Beberapa hasil riset Agung (2015) bahwa 'Terdapat pengaruh permainan tradisional terhadap peningkatan gerak motorik kasar berupa daya power, lari dan kelincahan pada siswa putra SD'. Mas'udin (2015) 'terdapat pengaruh permainan tradisional terhadap peningkatan VO2MAX. artinya bahwa permainan tradisional mampu membuat level kebugaran menjadi lebih baik.

\section{Bahan dan Metode}

Penggunaan bahan didasarkan pada kebutuhan dan karakteristik permainan olahraga yang berbeda di setiap minggunya. Sedangkan metode permainan olahraga tradisional menggunakan metode Play-Teach-Play yang disisipkan pada saat melakukan tahap pemanasan. Daftar permainan olahraga tradisional dan bahan dapat dilihat pada tabel di bawah ini: 


\section{Tabel 1 Jenis dan Pelaksanaan Permainan Olahraga}

\begin{tabular}{|c|l|l|l|l|}
\hline NO & \multicolumn{1}{|c|}{$\begin{array}{c}\text { Nama } \\
\text { Permainan }\end{array}$} & \multicolumn{1}{|c|}{ Tujuan } & \multicolumn{1}{c|}{ Bahan } & \multicolumn{1}{c|}{ Pelaksanaan } \\
\hline 1 & Ular Naga & $\begin{array}{l}\text { Menumbuhkan } \\
\text { Kerjasama dan } \\
\text { minat gerak }\end{array}$ & $\begin{array}{l}\text { Lakban hitam } \\
\text { untuk garis } \\
\text { pembatas ular } \\
\text { naga } \\
\text { Stopwatch dan } \\
\text { pluit }\end{array}$ & $\begin{array}{l}\text { Minggu ke-2 maret } \\
\text { (Masuk ke dalam materi } \\
\text { pemanasan) }\end{array}$ \\
\hline NO & $\begin{array}{c}\text { Nama } \\
\text { Permainan }\end{array}$ & \multicolumn{1}{|c|}{ Tujuan } & \multicolumn{1}{c|}{ Bahan } & \multicolumn{1}{c|}{ Pelaksanaan } \\
\hline 2 & Boy-boyan & $\begin{array}{l}\text { Menumbuhkan } \\
\text { kerjasama, gotong } \\
\text { royong dan minat } \\
\text { gerak }\end{array}$ & $\begin{array}{l}\text { Genting } \\
\text { Bola Plastik }\end{array}$ & $\begin{array}{l}\text { Minggu ke 3 maret } \\
\text { (Masuk ke dalam materi } \\
\text { pemanasan) }\end{array}$ \\
\hline 3 & Lari Balok & $\begin{array}{l}\text { Mengkoordinasikan } \\
\text { gerakan kaki dan } \\
\text { tangan, minat gerak } \\
\text { dan mental } \\
\text { berkompetisi secara } \\
\text { individu. }\end{array}$ & - Balok Kayu & $\begin{array}{l}\text { Minggu ke 4 maret } \\
\text { (Masuk ke dalam materi } \\
\text { pemanasan) }\end{array}$ \\
\hline 4 & Baren & $\begin{array}{l}\text { Kerjasama dan rasa } \\
\text { hormat ketika } \\
\text { dipimpin dan } \\
\text { memimpin }\end{array}$ & - Tiang Pembatas & $\begin{array}{l}\text { Minggu ke 1 april } \\
\text { (Masuk ke dalam materi } \\
\text { pemanasan) }\end{array}$ \\
\hline 5 & Jala Ikan & $\begin{array}{l}\text { Kebersamaan dan } \\
\text { minat gerak }\end{array}$ & $\begin{array}{l}\text { Minggu ke 2 april } \\
\text { (Masuk ke dalam materi } \\
\text { pemanasan) }\end{array}$ \\
\hline
\end{tabular}

Teknis sosialisasi dilaksanakan pada saat jam pelajaran olahraga di sekolah melibatkan tim pengabdian masayarakat program studi PGSD beserta mahasiswa tingkat dua. Permainan dilaksanakan di lapangan kampus Universitas Muhammadaiyah Tasikmalaya karena luas lapangan sekolah yang tidak memadai serta sarana yang dimiliki untuk menunjang permainan belum mencukupi.

\section{HASIL}

Dampak permainan olahraga tradisional pada siswa sekolah dasar tergantung pada jenis permainan yang dimainkan oleh peserta didik pada saat pelaksanaan tim telah memainkan dua olahraga tradisional dengan dampaknya pada subjek:

1. Ular naga

Pada saat permainan ular naga peserta didik merasakan bagaiman mata pelajaran pendidikan jasmani bukan lagi kegiatan yang melelahkan ataupun sekedar berkeringat. Dari data kualitatif tim pengabdian memperoleh data minat gerak secara signifikan daalam artian siswa lebih aktif dan ceria.

2. Kucing dan tikus 
Pelaksanaan permainan kucing dan tikus melibatkan seluruh siswa yang ada di kelas. Dari data kualitatif yang diperoleh siswa mampu bekerja sama antar teman sebayanya, mengurangi rasa egois karena permainan menuntut adanya kerjasama tim. Untuk mencapai kemenangan tim diperlukan kerjasama secara tim jika salah satu tidak bisa menahan diri untuk berlari atau mengejar lawan maka dipastikan seluruh tim akan kehilangan kesempatan menang.

3. Lari Balok

Karakteristik permainan lari balok ialah mengkoordinasikan gerak antara kaki dan tangan. Perpindahan tangan ke balok dan kaki agar tidak berpijak pada tanah memerlukan tingkat kesabaran yang tinggi. Permainan ini menghasilkan para siswa untuk memenangi kompetisi dengan perhitungan yang matang sehingga tidak mengambil keputusan secara terburu-buru yang mengakibatkan kerugian pada diri sendiri.

Dari ketiga permainan tersebut mengindikasikan bahwa pembelajaran pendidikan jasmani mampu meningkatkan kebugaran siswa dalam aspek daya tahan. Sedangkan dalam aspek psikis yang dilaksanakan dalam kehidupan sehari-hari siswa mampu membiasakan hidup sehat dan rajin berolahraga.

\section{PEMBAHASAN}

Salah satu tujuan proses pembelajaran pendidikan jasmani, Olahraga dan Kesehatan di sekolah dasar ialah meningkatkan keterampilan gerak dasar siswa. Gerak dasar berjalan, berlari dan melompat merupakan gerak dasar lokomotor yang perlu dikembangkan di sekolah dasar (SD). Gerak dasar lokomotor berada pada level gerak dasar fundamental (fundamental basic movement), di samping gerak dasar non-lokomotor dan gerak dasar manipulatif, gerak dasar lokomotor yang merupakan pokok bahasan yang diajarkan disekolah dasar (SD). Lutan (2001: 21) "menyatakan bahwa kemampuan gerak dasar dapat diterapkan dalam aneka permainan, olahraga, dan aktivitas jasmani yang dilakukan sehari-hari".

Melalui aktivitas bermain, sangatlah tepat untuk mengembangkan keterampilan gerak dasar anak di sekolah dasar, karena pada dasarnya dunia anak-anak adalah dunia bermain. Kemampuan gerak dasar dapat diterapkan dalam aneka permainan, olahraga, dan aktivitas jasmani yang dilakukan sehari-hari. Permainan tradisional merupakan salah satu jenis permainan yang dapat memberikan manfaat untuk perkembangan pertumbuhan anak. Permainan tradisional mempunyai hubungan yang erat dengan perkembangan intelektual, sosial, serta karakter anak.

Di sekolah, permainan tradisional dapat diperkenalkan melalui pendidikan jasmani. Karena pendidikan jasmani merupakan proses pendidikan melalui penyediaan pengalaman belajar kepada peserta didik berupa aktivitas jasmani, bermaian, dan berolahraga yang direncanakan secara sistematis guna merangsang pertumbuhan dan perkembangan fisik, organik, keterampilan motorik, keterampilan berfikir, emosional, sosial dan moral. Pembekalan pengalaman belajar itu diarahkan untuk membina, sekaligus membentuk gaya hidup sehat dan aktif sepanjang hayat.

Permainan tradisonal merupakan simbolisasi dari pengetahuan yang turun temurun dan mempunyai bermacam-macam fungsi atau pesan di baliknya, di mana pada prinsipnya permainan anak tetap merupakan permainan anak. Dengan demikian bentuk atau wujudnya tetap menyenangkan dan menggembirakan anak karena tujuannya sebagai media permainan. 
Aktivitas permainan yang dapat mengembangkan aspek-aspek psikologis anak dapat dijadikan sarana belajar sebagai persiapan menuju dunia orang dewasa.

Seluruh permainan tradisional yang dilakukan tujuannya adalah untuk berolahraga, mengisi waktu luang dan memupuk sikap kerja sama (kekompakan team). Manfaat permainan ini adalah untuk meningkatkan kebugaran, ketegangan menurun, dan kemampuan kerja sama meningkat. Unsur gerak dasar yang ada dalam permainan ini adalah berjalan dan berlari.

\section{KESIMPULAN DAN SARAN}

Salah satu tujuan pelaksanaan pendidikan jasmani, Olahraga dan Kesehatan di sekolah dasar adalah meningkatkan kemampuan dan keterampilan gerak dasar. Kemampuan gerak dasar dapat diterapkan dalam aneka permainan, olahraga, dan aktivitas jasmani yang dilakukan seharihari. Permainan tradisional merupakan salah satu jenis permainan yang dapat memberikan manfaat untuk perkembangan pertumbuhan anak sekolah dasar sebab permainan tradisional dikemas untuk membentuk gerak dasar berlari, berjalan, meloncat, menghindar, menangkap, menggiring, merayap dan lain-lain. Permainan tradisional yang dapat membentuk gerak dasar untuk siswa sekolah dasar berbagai macam bentuknya, diantaranya adalah permainan tradisional ular naga, kucin dan tikus. Dalam pelaksanaan pengabdian tidak terlepas dari kekeliruan atau hal-hal tidak diprediksi maka penulis memberikan saran bahwa olahraga tradisonal harus diberikan pada sesi pemanasan dalam pembelajaran olahraga.

\section{UCAPAN TERIMA KASIH}

Keberhasilan Pelaksanaan pengabdian dan penyusunan laporan pengabdian tidak terlepas dari peran serta pihak-pihak yang mendukung sehingga selesai tepat pada waktunya. Adapun pihak-pihak yang mendukung ialah:

1. Rektor Universitas Muhammadiyah (UMTAS)

2. Lembaga Penelitian dan Pengabdian Masyarakat UMTAS

3. Dosen-dosen program studi PGSD UMTAS

4. Sekolah Dasar Setiamulya 1 dan 2 yang telah bersedia menjadi mitra

5. Mahasiswa PGSD yang telah terlibat dalam tim pengabdian masyarakat

Serta seluruh pihak yang tidak bisa penulis sebutkan satu persatu semoga dukungan ini dibalas oleh Allah Swt.

\section{Daftar Pustaka}

Lutan, R. (2001). Belajar dan Pembelajaran. Jakarta: Depdikbud. Direktorat Jenderal Pendidikan Tinggi. Proyek Pendidikan Akademi.

Agung, A. (2015). Pengaruh Permainan Tradisional Terhadap Peningkatan Kemampuan Gerak Motorik Kasar Pada Siswa Putra Sekolah Dasar. Semarang: UNNES. [ONLINE].lib.unnes.ac.id

Mas'udin (2015). Pengaruh permainan tradisional bebentengan terhadap penigkatanVO2MAX peserta ekstrakurikuler pencaksilat di SMP negeri 26 purworejo. Yogyakarta: UNY.[ONLINE].

eprints.uny.ac.id 


\section{LAMPIRAN}

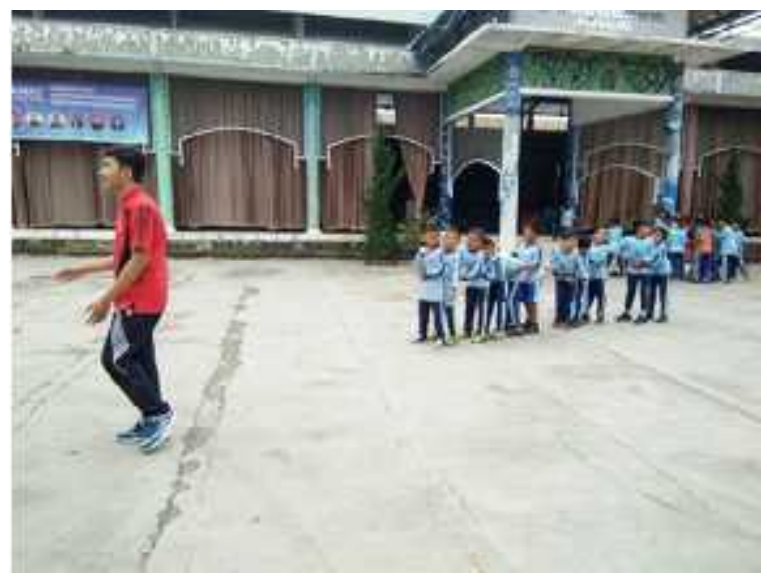

Gambar 1. Praktek Permainan Ular Naga

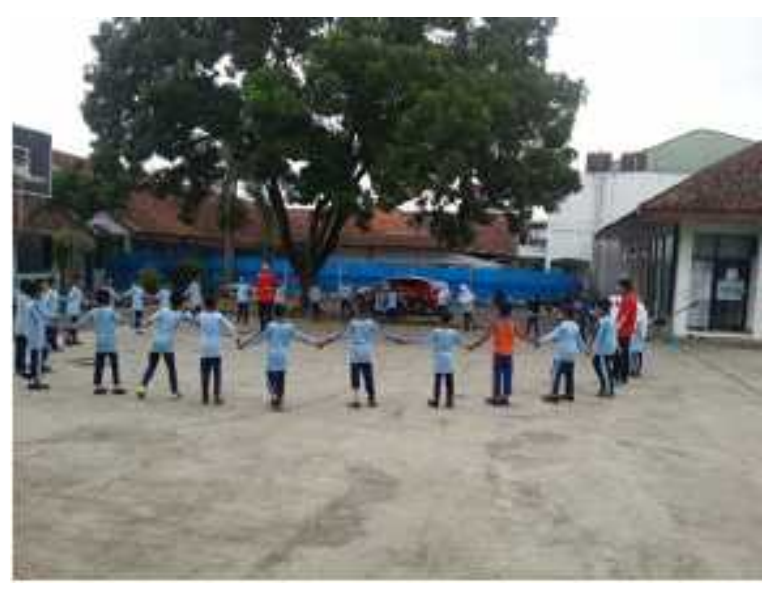

Gambar 2. Permainan Kucing dan Tikus

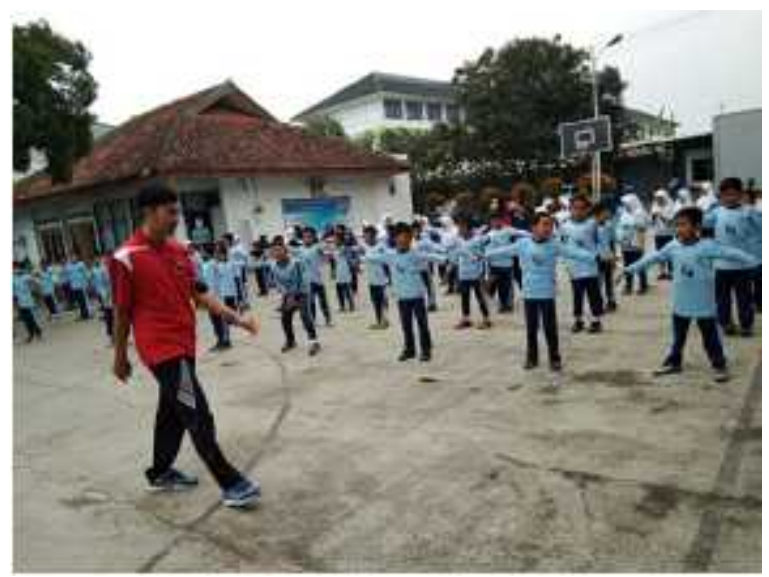

Gambar 3. Proses Warming-Up 